OPEN ACCESS

Edited by:

Gregory Light,

University of California, San Diego,

United States

Reviewed by:

Yegang $\mathrm{Hu}$,

Shanghai Jiao Tong University, China Yash Joshi,

University of California, San Diego, United States

${ }^{*}$ Correspondence:

Zafiris J. Daskalakis Jeff.Daskalakis@camh.ca

Specialty section:

This article was submitted to Schizophrenia,

a section of the journal

Frontiers in Psychiatry

Received: 23 April 2020

Accepted: 24 July 2020

Published: 07 August 2020

Citation:

Kim HK, Blumberger DM and Daskalakis ZJ (2020) Neurophysiological Biomarkers

in Schizophrenia-P50,

Mismatch Negativity, and TMS-EMG and TMS-EEG.

Front. Psychiatry 11:795. doi: 10.3389/fpsyt.2020.00795

\section{Neurophysiological Biomarkers in Schizophrenia-P50, Mismatch Negativity, and TMS-EMG and TMS-EEG}

\author{
Helena K. Kim ${ }^{1}$, Daniel M. Blumberger ${ }^{1,2}$ and Zafiris J. Daskalakis ${ }^{1,2 *}$ \\ 1 Department of Psychiatry, University of Toronto, Toronto, ON, Canada, 2 Temerty Centre for Therapeutic Brain Intervention, \\ Centre for Addiction and Mental Health, Department of Psychiatry, University of Toronto, Toronto, ON, Canada
}

Impaired early auditory processing is a well characterized finding in schizophrenia that is theorized to contribute to clinical symptoms, cognitive impairment, and social dysfunction in patients. Two neurophysiological measures of early auditory processing, P50 gating ("P50") and mismatch negativity (MMN), which measure sensory gating and detection of change in auditory stimuli, respectively, are consistently shown to be impaired in patients with schizophrenia. Transcranial magnetic stimulation (TMS) may also be a potential method by which sensory processing can be assessed, since TMS paradigms can be used to measure $\mathrm{GABA}_{\mathrm{B}}$-mediated cortical inhibition that is linked with sensory gating. In this review, we examine the potential of P50, MMN and two TMS paradigms, cortical silent period (CSP) and long-interval intracortical inhibition (LICI), as endophenotypes as well as their ability to be used as predictive markers for interventions targeted at cognitive and psychosocial functioning. Studies consistently support a link between MMN, P50, and cognitive dysfunction, with robust evidence for a link between MMN and psychosocial functioning in schizophrenia as well. Importantly, studies have demonstrated that MMN can be used to predict performance in social and cognitive training tasks. A growing body of studies also supports the potential of MMN to be used as an endophenotype, and future studies are needed to determine if MMN can be used as an endophenotype specifically in schizophrenia. P50, however, has weaker evidence supporting its use as an endophenotype. While CSP and $\mathrm{LICl}$ are not as extensively investigated, growing evidence is supporting their potential to be used as an endophenotype in schizophrenia. Future studies that assess the ability of P50, MMN, and TMS neurophysiological measures to predict performance in cognitive and social training programs may identify markers that inform clinical decisions in the treatment of neurocognitive impairments in schizophrenia.

Keywords: P50, mismatch negativity, schizophrenia, biomarker, early sensory processing 


\section{INTRODUCTION}

Impaired auditory processing is a consistent finding in schizophrenia and is thought to lead to failures in one's ability to interact with the environment, contributing to delusional beliefs, hallucinations, social withdrawal, cognitive dysfunction, and decline in functioning (1-10). These deficits have been extensively studied using event-related potentials (ERP) corresponding to early sensory processing events that occur within milliseconds following the reception of an auditory stimulus (7). Mismatch negativity (MMN) and P50 are ERPs that have been extensively studied to examine auditory processing deficits in patients with schizophrenia (11-14). In addition, transcranial magnetic stimulation (TMS), which is an experimental modality with high test-retest reliability, can be used to explore molecular pathways involved in cortical inhibition that are associated with gating of auditory stimuli $(15-18)$. MMN is evoked when there is a rare interruption in a repetitive sequence of stimuli by an "oddball" stimulus that differs from the original sequence by a specific physical quality, such as duration or pitch $(19,20)$. Deficits in MMN have been associated with decreased ability to orient to critical events occurring in the surrounding environment as well as impaired detection of sensory information that enables identification of social cues (7). Decrease in MMN amplitude has been reported by multiple studies in schizophrenia using a wide range of deviant stimulus characteristics (21-23). P50 is used to assess sensory gating, which represents inhibition of response to a repetitive stimulus (24). Sensory gating is thought to prevent organisms from receiving an overwhelming amount of information from the environment by minimizing response to redundant and irrelevant stimuli (25). Increased ratio of P50 to the redundant auditory stimulus compared to the original stimulus, termed P50 gating ratio, has been shown in patients with schizophrenia (26-39). $\mathrm{GABA}_{\mathrm{B}}$ receptor-mediated cortical inhibition, which is thought to underlie sensory gating (40), can also be measured using TMS markers, which were shown to be altered in patients with schizophrenia (41), presenting an alternative method to explore neurological processes involved in early sensory processing deficits (15-18). Dysfunction of such neurophysiological filtering may contribute to clinical symptoms and cognitive dysfunction in schizophrenia (42-44).

Biomarkers can aid the identification of molecular pathways, such as genes, underlying a particular disease and/or act as predictive markers to define interventions. While certain biomarkers can serve both functions, some are best suited for one of these purposes. Endophenotypes are conventionally regarded as biological measures that are thought to be closely related to the genetic variation responsible for causing upstream changes, and thus can help understand the molecular mechanisms underlying pathophysiology $(45,46)$, where recently proposed endophenotypes in schizophrenia have included EEG markers $(47,48)$. Predictive biomarkers, on the other hand, are those identified using a different set of criteria, as specified by the Measurement and Treatment Research to Improve Cognition in Schizophrenia (MATRICS) initiative, to aid in the development and selection of interventions, with an

emphasis on association with a functional outcome and/or pharmacological response (49). Recent studies have explored EEG and neuroimaging markers as predictors of treatment response $(50,51)$, demonstrating a growing interest in identifying non-invasive endophenotypes and biomarkers in schizophrenia. Characteristics of an endophenotype and a predictive biomarker are summarized in Table $\mathbf{1}$.

MMN and P50 are among the neurophysiological markers that are being considered as potential endophenotypes in this disease (52-54). In addition, as MMN and P50 are markers of neurological processes that are thought to be important for cognitive functioning in patients with schizophrenia, they have also garnered interest as predictive biomarkers to see if an intervention will improve cognition (55-60). Tolerability and practicality of ERP measurements are well understood, but their relationship with cognitive and psychosocial outcomes has yet to be fully elucidated $(7,12)$. TMS paradigms can also be used as an additional modality to explore deficits that may contribute to sensory abnormalities in schizophrenia by altering cortical inhibition. Therefore, in this review, we aimed to provide an updated overview of studies that have examined the potential of P50, MMN, and TMS paradigms to be used as endophenotypes in schizophrenia, as well as their relationship with psychosocial and cognitive functioning in patients to examine their potential to be used as predictive biomarkers for interventions targeted at these domains.

\section{MISMATCH NEGATIVITY}

MMN is evoked passively when there is a rare oddball stimulus that is presented as an interruption to a sequence of repetitive identical stimuli that occurs within $50 \mathrm{~ms}$ after the presentation of the oddball and peaks between 100-200 ms $(13,20)$. MMN is followed by another ERP component, P3a, that peaks between $250-300 \mathrm{~ms}$ that is thought to represent the shifting of attention to the oddball stimulus, and another ERP known as RON that peaks between $400-500 \mathrm{~ms}$ that is thought to reflect the reorientation of attention to detect further changes in the stimulus $(61,62)$. While MMN has been most extensively studied within the oddball paradigm and consistently shown to be decreased (i.e., less negative compared to controls) in different stages of schizophrenia $(12,14,22,23,63-82), \mathrm{P} 3 \mathrm{a}$, and more

TABLE 1 | Characteristics of an endophenotype and a predictive biomarker.

Endophenotype $(45,46)$

Heritability

Test-retest reliability

Trait stability (i.e. lack of change with pharmacological interventions or disease progression)

Diagnostic specificity

Greater prevalence in patients compared to the general population
Predictive biomarker (49)

Relationship with a functional outcome Test-retest reliability Response to pharmacological agents

Utility as a repeated measure

Practicality and tolerability 
recently, RON, have also been shown to be impaired in patients with schizophrenia (81, 83-86).

A large body of studies has demonstrated decreased MMN in schizophrenia using different deviant stimuli, with one study reporting an effect size of 0.99 between patients and healthy controls $(19,22,23,67,87,88)$. MMN also has good test-retest ability, with studies reporting moderate to high interclass correlation coefficients (ICC) $(22,58,89)$. The evidence for trait stability in $\mathrm{MMN}$ is mixed. A recent meta-analysis demonstrated that MMN is stable throughout the different stages of schizophrenia (90), while an older meta-analysis showed that MMN to frequency deviant stimuli correlated with illness duration (23). Also, MMN was shown to vary with nicotine, suggesting changes with pharmacological interventions (91). There are also a number of studies demonstrating that MMN varies with the presence and severity of positive and/or negative symptoms measured by scales such as the positive and negative syndrome scale (PANSS) or the psychotic symptom rating scale (PSYRATS) $(66,75,85,87,92-97)$, while evidence to the contrary exists as well $(22,23,70,74,78,81,98,99)$. While many studies have consistently reported decreased MMN in schizophrenia, a meta-analysis by Erickson and colleagues have shown that MMN impairment is also present in patients with bipolar disorder (BD) (90). For heritability, Hall and colleagues reported significant heritability for MMN at $63 \%$ and $68 \%$ for peak amplitude and mean amplitude, respectively (89). An aforementioned meta-analysis showed that there was a trend for decreased MMN amplitude in relatives of patients (90), which was in agreement with another meta-analysis (100). A recently published study also demonstrated an intrinsic effect of 22q11.2 deletion syndrome, a molecular risk factor for schizophrenia, on MMN (54), suggesting a potential genetic link as well. Therefore, while a growing body of studies is supporting MMN as an endophenotype, the findings are mixed. Replication of these findings in future studies will help further demonstrate if MMN can be used as an endophenotype.

MMN has been consistently shown to correlate with various cognitive processes $(9,63,101-104)$. Toyomaki and colleagues (105) reported that MMN amplitude was associated with executive functioning as measured by the Wisconsin Card Sorting Test (WCST), Stroop test and trail making test. Supporting this, verbal executive function and verbal IQ were associated with MMN amplitude in patients with schizophrenia (67) and verbal memory was enhanced in patients with prolonged MMN to frequency deviant stimuli (92). On the other hand, Kawakubo and colleagues reported that lower amplitude of MMN is associated with worse verbal memory but not with executive function in patients with schizophrenia (106). This difference in findings between studies may be because MMN amplitude change to different types of deviant stimuli may represent different changes that occur in the brain (92). For example, MMN amplitude change produced by duration and intensity deviance are identifiable in earlier stages of schizophrenia, while amplitude changes to frequency deviance may become more prominent in later stages of the illness (64, 93). The association between poor performance on cognitive tests and MMN amplitude abnormalities in patients with schizophrenia may have implications for daily functioning, as MMN deficits were found to be correlated with greater errors in identification of environmental sounds that are functionally relevant (19). Also, patients with higher MMN amplitude showed greater improvement after auditory perceptual training exercises, suggesting that MMN may be used as a predictive marker in schizophrenia as well (107). Furthermore, when early auditory processing (EAP) was measured by combining MMN, $\mathrm{P} 3 \mathrm{a}$ and RON, it was found that EAP was directly associated with a comprehensive assessment of cognitive functioning as measured by the letter number span test, California verbal learning test, Weschler memory scale, and Penn computerized neurocognitive battery (1).

Poor psychosocial functioning as measured by scales such as the global assessment of functioning scale (GAF) and independent living scale (ILS) is considered to be one of the most consistent findings associated with lower MMN amplitude in schizophrenia $(9,22,63,64,99,106,108,109)$. Supporting this, patients with greater reductions in MMN amplitude were found to be less likely to live in independent settings (22). Also, using the social and occupational functioning assessment scale, lower MMN amplitude was correlated with lower day-to-day functioning (110). Furthermore, when patients with schizophrenia were asked to perform a series of tasks that measured skills necessary for daily functioning, it was found that peak MMN amplitude differences accounted for a significant portion of the variance in performance (9). Wynn and colleagues (108) also reported that higher MMN amplitude was correlated with independent living and higher social perception, possibly contributing to better ability to function in the real world. Supporting this, when patients with schizophrenia received social skills training for 3 months and were assessed on their total social skill scores using a structured role play test, MMN current density values predicted the degree of improvement in patients (63). Interestingly, when $\mathrm{MMN}, \mathrm{RON}$, and P3a measurements were used to quantify the EAP, it was found that EAP had a significant association with functional outcome that was mediated by general cognition or negative symptoms (1), suggesting a link between clinical symptoms, cognitive and psychosocial functioning. On the other hand, one study showed that while $\mathrm{P} 3 \mathrm{a}, \mathrm{MMN}$ and $\mathrm{RON}$ amplitudes were associated with psychosocial functioning as assessed with GAF in patients with chronic schizophrenia, this association was not found in patients with a recent onset (81). Also, a recently published study showed that MMN was not correlated with improvement in community functioning or performance on cognitive tasks after cognitive training (60). (1)

\section{P50}

P50 gating (or P50 suppression; "P50") is a measure of sensory gating, which is thought to be one of the mechanisms underlying positive symptoms of schizophrenia since failure to gate unnecessary sensory input and consequent sensory overload is 
thought to contribute to hallucinations (26-30). P50 has been used to study auditory processes in schizophrenia for more than 30 years, where subjects are presented with two auditory stimuli that are separated from each other by $500 \mathrm{~ms}$, and the amplitude of the evoked potentials at $50 \mathrm{~ms}$ and $100 \mathrm{~ms}$ after each stimulus are classified as P50 and N100, respectively $(26,111,112)$. The initial stimulus is termed $\mathrm{S} 1$, or conditioning stimulus (C), and the second stimulus is termed S2, or test stimulus (T), where the $\mathrm{T} / \mathrm{C}$ ratio of less than $50 \%$ is typically considered to be normal gating $(24,31)$.

Patients with schizophrenia are consistently reported to have increased $\mathrm{T} / \mathrm{C}$ ratios, also known as $\mathrm{P} 50$ gating deficits, including in meta-analyses $(7,27,29,37,111,113,114)$. N100 gating has also been reported to be deficient in patients with schizophrenia $(44,115)$. P50 gating has gathered much attention as a potential endophenotype in part because of a genetic association with a polymorphism in the promotor region of the $\alpha 7$-nicotinic cholinergic receptor gene (CHRNA7) (116), which was found to be more common in patients with schizophrenia than controls and associated with gating deficiency (117). P50 also has an established biological basis through activation of the $\mathrm{GABA}_{\mathrm{B}}$ receptors on glutamatergic afferents, resulting in inhibition of pyramidal neurons from firing, which is thought to be impaired in schizophrenia $(40,118)$. This suggests, however, that P50 may be affected by pharmacological agents that act through the same receptor and therefore less likely to be a trait marker. Indeed, clozapine was shown to improve P50 gating in patients with schizophrenia, likely related to potentiation of the $G_{A B A}$ receptor (119). It has also been shown that while P50 may not be affected by agents that almost exclusively target dopaminergic neurotransmission, it is affected by atypical antipsychotics, such as clozapine and olanzapine $(42,119,120)$. Studies have also demonstrated that $\mathrm{P} 50$ gating ratios differ with intensity, severity and frequency of hallucinations $(26,121-124)$, although the evidence for this is weak, as there are studies demonstrating the opposite as well $(30,120,125-128)$. The same was found for negative symptoms, where studies have both demonstrated a lack of association with P50 (24, 30, 39, 120, 125, 126, 129-132) as well as a significant relationship $(43,133)$. Outside of positive and negative symptoms of schizophrenia, impaired P50 gating was found to be associated with anxiety, depression and anergia in patients who were recently diagnosed with schizophrenia (130). Therefore, evidence suggests that P50 is likely not a trait stable marker, although it is uncertain if it is a state marker. Studies also showed that P50 lacks in diagnostic specificity, as P50 suppression was found in patients with $\mathrm{BD}$, relatives of patients with psychotic BD (134), and Alzheimer's disease (135, 136). For heritability, a meta-analysis by de Wilde and colleagues showed a moderate to large effect size for P50 in relatives of patients with schizophrenia (114). Twin studies have also reported a significantly higher ICC for monozygotic twins compared to dizygotic twins $(137,138)$, suggesting heritability, with one study reporting heritability for the T/C ratio to be $68 \%$ (89). On the other hand, a study examined 183 nuclear families of patients with schizophrenia and found that heritability was not statistically significant (139). Lastly, P50 has been shown to have low test-retest reliability (58), with ICC being shown to be less than 0.5 in one study (33). However, another study reported that P50 gating ratio had a ICC of 0.66 (89), suggesting that the findings are inconsistent.

The relationship between P50 gating deficiencies and cognitive functioning has been extensively studied $(8,11,24$, 140). Patients with schizophrenia who were classified as having a high gating abnormality according to their P50 gating ratios were found to have impaired sustained attention (30). This was in agreement with several studies that also showed an association between impairment in P50 gating and poor attention, working memory and lower processing speed $(24,26,30,121,130,141$, 142). Furthermore, in one study, P50 and N100 amplitudes were able to predict working memory, attention, and long delayed memory, where variance in attention remained significantly associated with P50 even after correcting for general cognitive ability as measured by IQ (121). Interestingly, one study showed that P50 gating deficiencies were associated with worse performance on the color pattern implicit learning task, suggesting that this gating deficiency may extend to other areas of learning as well (143). The same study demonstrated that P50 gating deficit may have different effects on visual and auditory learning, as one study found that P50 gating impairment was correlated with visual but not with verbal implicit memory test performance (143). In contrast, Cullum and colleagues reported that P50 gating ratio is not correlated with processing speed (26). Using the WCST and Repeatable Battery for the Assessment of Neuropsychological Status (RBANS), three studies also found a lack of relationship between P50 ratio and cognitive functioning $(30,59,126)$.

While the relationship between P50 gating and psychosocial or global functioning have not been as extensively examined as for $\mathrm{MMN}$, one study reported that patients with impaired P50 gating have worse community outcome (113), where they were found to have worse GAF scores and lower quality of life scores, suggesting that sensory gating impairments may contribute to functional impairment as well $(8,113)$.

\section{TMS-EMG AND TMS-EEG PARADIGMS}

TMS uses magnetic fields to induce eddy currents in the cortex through electromagnetic induction (144). It is unique in that it can differentially stimulate inhibitory interneurons and pyramidal neurons, allowing for the measurement of GABA receptor-mediated inhibition (17), which was shown to be impaired in schizophrenia $(40,41,145)$. Animal models have shown a direct link between $\mathrm{GABA}_{\mathrm{B}}$ receptor blockade and impaired sensory gating $(146,147)$. These findings, together with studies demonstrating the involvement of $\mathrm{GABA}_{\mathrm{B}}$ activation in sensory gating as measured by P50 in humans (40), suggest that TMS paradigms for measuring $\mathrm{GABA}_{\mathrm{B}}$ receptor-mediated cortical inhibition can be used to examine sensory gating in schizophrenia $(17,18,144)$. Two TMS paradigms that can provide a measure of $\mathrm{GABA}_{\mathrm{B}}$ receptor inhibition are long interval cortical inhibition (LICI) and the 
cortical silent period (CSP) (15-17). LICI is analogous to the P50 paradigm, where a suprathreshold conditioning stimulus is followed by a suprathreshold test stimulus by $50-200 \mathrm{~ms}$, producing an inhibition of the motor evoked potential (MEP) by $50 \%$ (148). LICI can also be examined using TMS-EEG by measuring P30, which is an early TMS-evoked cortical potential (149). CSP uses stimulation to the motor cortex which, at high intensities, causes cessation of all background EMG activity that is normally ongoing, where the duration of the "silent period" is measured to quantify the extent of GABAergic inhibition (150). EEG indices of CSP have also been explored, where power of alpha and delta oscillations were found to be related to CSP duration (151). Importantly, CSP and P50 were found to be significantly correlated (152), providing additional evidence that they work through the same mechanism $(17,153,154)$ Furthermore, CSP was found to be impaired in patients with schizophrenia $(41,155)$, suggesting that CSP may be a good candidate for the study for $\mathrm{GABA}_{B}$ receptor inhibition in schizophrenia, which is implicated in sensory gating deficits in this population. (156)

TMS paradigms have more recently emerged as potential endophenotypes of schizophrenia. Several findings support LICI and CSP as indices of $G_{A B A}$ receptor inhibition, including the ability of baclofen, a GABA $\mathrm{B}_{\mathrm{B}}$ agonist, to increase LICI and CSP duration $(153,154)$, and the fact that slow inhibitory postsynaptic potentials mediated by $\mathrm{GABA}_{B}$ receptors peak at 150 s, which is the duration of LICI and CSP (17). These studies support a biological basis for these TMS paradigms. It was also demonstrated that TMS measures have a high test-retest reliability with ICC being greater than 0.8 in the motor cortex (18). One study examining prefrontal cortex LICI in patients with schizophrenia, obsessive compulsive disorder, and healthy controls found that LICI deficit was specific to schizophrenia (157), suggesting diagnostic specificity. For heritability, a lack of difference in LICI was found between first degree relatives of patients with schizophrenia and controls (158), while the heritability of CSP has yet to be examined. One study examining CSP in patients with chronic schizophrenia, recentonset schizophrenia, and healthy controls reported a significant difference between the three groups, which was driven by the shorter CSP in recent-onset patients compared to health controls (159). In addition to baclofen, CSP was reported to increase with clozapine and quetiapine (160-162), while one study reported no difference in CSP between medicated and un-medicated patients (163). On the other hand, LICI was not found to differ with cannabis use in patients with schizophrenia (164), and transcranial direct current stimulation failed to modulate CSP in patients with schizophrenia (165). While these studies show mixed findings for trait stability, they suggest a potential for CSP and LICI to be used as markers of treatment response with certain medications as it shows modulation with pharmacological agents. TMS is also a non-invasive procedure with high tolerability $(166,167)$, making it ideal for the use of identification of endophenotypes and/or predictive markers.

CSP and LICI have not been extensively examined for their potential to be used as predictive biomarkers in schizophrenia.
One study examined the relationship between LICI and social cognition and did not find a significant correlation (156). While more studies are needed to identify if TMS paradigms can be used as predictive biomarkers for cognitive and social functioning, their high-test retest reliability and clear association with a biological pathway suggest that it may be a promising avenue to explore for the identification of endophenotypes and/or predictive biomarkers for pharmacological agents that may impact sensory processing.

\section{DISCUSSION}

Deficits in EAP have been extensively studied in patients with schizophrenia, where they are thought to contribute to failures in detecting important environmental cues and filtering of irrelevant stimuli, possibly leading to social withdrawal, hallucinations, cognitive dysfunction, and decreased level of overall day-to-day functioning $(1,3,4,6,7,9,10,12,19,88$, $100,114,168)$. Here, we reviewed studies examining if MMN and P50 meet the 5 criteria for a marker to be considered an endophenotype (46), as well as their relationship with cognitive and psychosocial functioning to examine their potential to be used as markers to inform interventions targeted at improving these domains. Furthermore, we examined two TMS paradigms, CSP and LICI, for their potential to be used as markers of sensory gating and as endophenotypes in schizophrenia. A diagram summarizing the findings discussed in this review can be found in Figure 1.

Impairment in $\mathrm{MMN}$ is consistently demonstrated in patients with schizophrenia $(14,19,88)$ with studies showing moderate to high test-retest reliability $(58,89)$. However, studies examining heritability, trait stability and diagnostic specificity of MMN have reported mixed findings $(89,90,100)$ suggesting that while promising, future studies further demonstrating MMN's suitability as an endophenotype for schizophrenia would be beneficial. A significant correlation between MMN and performance in cognitive tasks is consistently reported in schizophrenia (80). Furthermore, MMN amplitude was able to predict how a patient would perform in auditory perceptual training exercises (107), suggesting its utility as a predictive marker as well. $(1,11)$. Studies have also consistently shown that lower MMN is correlated with poor psychosocial functioning and ability to live in independent settings $(1,11,22,88,108,109$, 169). Furthermore, $M M N$ was also able to predict performance in social skills training in patients with schizophrenia, again demonstrating its ability to be used as a predictive marker (63), although evidence for the contrary exists as well (60). These studies demonstrate the potential for MMN to be used as a surrogate marker/endpoint and a predictive marker for cognitive and psychosocial dysfunction.

P50 is a marker of sensory gating, which is thought to be an important cognitive process involved in the development of schizophrenia $(11,24,141)$. Like MMN, impaired P50 gating is consistently reported in patients with schizophrenia compared to healthy controls $(111,114)$. While P50 has a strong link to the CHRNA7 gene and the $\mathrm{GABA}_{\mathrm{B}}$ receptor $(116,117,152)$, the 


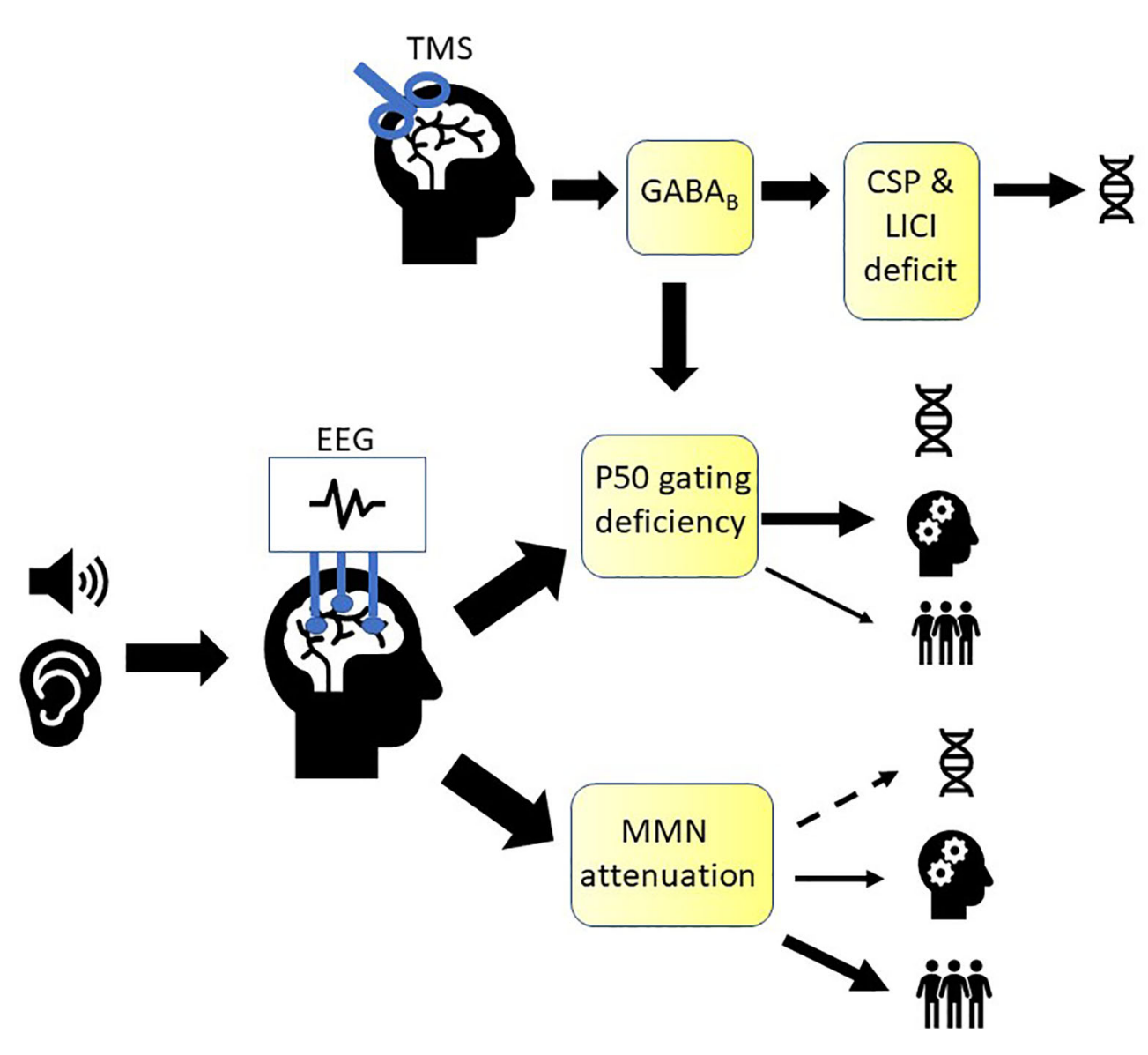

FIGURE 1 | Summary of markers of early auditory sensory processing in schizophrenia. A growing body of evidence is supporting mismatch negativity (MMN) as an endophenotype in schizophrenia (denoted by the DNA icon), while evidence is weaker for P50. Both were shown to be associated with cognitive functioning (denoted by the cogwheel icon) and psychosocial functioning (denoted by the people icon). P50 gating ratio is thought to represent in part GABAB receptormediated cortical inhibition, which can also be measured using TMS (transcranial magnetic stimulation) paradigms, cortical silent period (CSP) and long-interval intracortical inhibition (LICI). CSP and $\mathrm{LICl}$ are promising candidates for endophenotypes that can be used to study sensory gating in schizophrenia.

evidence for P50 as an endophenotype of schizophrenia is inconsistent for heritability, test-retest reliability, and heritability $(24,39,58,89,120,122,133,134,139,170)$ suggesting that more studies are required to ascertain if P50 can be used as an endophenotype in schizophrenia. Sensory gating is also thought to play an important role in various cognitive processes (140), and accumulating evidence is supporting an association between P50 gating deficiencies and cognitive deficits $(8,26,29,121,141,143)$, although there are studies reporting the contrary $(26,30,126)$. Evidence is also accumulating for N100 gating ratio and its potential to act as a marker for cognitive functioning in patients with schizophrenia $(44,58,112,121)$. While the relationship between P50 gating ratio and psychosocial and global functioning has not been extensively examined, (8) one study reported an association between P50 gating ratio deficit and poor community outcome (113). Together, these studies suggest that more studies are needed to elucidate the link between P50 and global functioning, while P50 may hold promise as a marker of cognitive impairment in schizophrenia.
$\mathrm{GABA}_{\mathrm{B}}$ receptor-mediated cortical inhibition is implicated in sensory gating $(147,171)$, which can be measured using two TMS paradigms, LICI and CSP $(16,17)$. Several lines of evidence support LICI and CSP as measures of GABAergic inhibition, including increased duration with a $\mathrm{GABA}_{\mathrm{B}}$ agonist, baclofen $(153,154)$. Furthermore, CSP was found to be significantly correlated with P50 (152), suggesting that it may be used as a marker to study $\mathrm{GABA}_{\mathrm{B}}$ receptor-mediated cortical inhibition in schizophrenia. TMS measures have a high test-retest reliability (18) and accumulating evidence is demonstrating impaired CSP and $\operatorname{LICI}(41,155)$ in patients with schizophrenia, which may be specific to this diagnosis (160). Studies examining trait stability of CSP and LICI report mixed findings (160-165), and more studies are needed to establish heritability of these markers in schizophrenia. Together, these findings suggest that CSP and LICI are promising potential endophenotypes to examine sensory processing deficits in schizophrenia, although more studies are needed (152).

In summary, there is an accumulating body of evidence is supporting a link between P50, MMN and cognitive functioning 
in schizophrenia. Future studies are needed to assess the ability of P50 and MMN to inform clinical decisions as predictive biomarkers in the treatment of schizophrenia. While MMN is also correlated with global and psychosocial functioning, their association with P50 has not been extensively studied (92, 108, 109). Future studies may benefit from exploring the relationship between P50 and functional outcomes in schizophrenia as well to further understand the contribution of early sensory processing deficits in functional outcomes in this disease. P50 has inconsistent evidence at this time to support its suitability as an endophenotype, suggesting that it may represent more dynamic processes influenced by internal and external changes rather than upstream, genetically linked processes that are stable throughout the course of one's life. On the other hand, studies

\section{REFERENCES}

1. Thomas ML, Green MF, Hellemann G, Sugar CA, Tarasenko M, Calkins ME, et al. Modeling deficits from early auditory information processing to psychosocial functioning in Schizophrenia. JAMA Psychiatry (2017) 74 (1):37-46. doi: 10.1001/jamapsychiatry.2016.2980

2. Vinogradov S, Nagarajan S. Association of sensory processing with higherorder cognition and functioning in Schizophrenia: Mapping the World. JAMA Psychiatry (2017) 74(1):17-8. doi: 10.1001/jamapsychiatry.2016.2992

3. Force RB, Venables NC, Sponheim SR. An auditory processing abnormality specific to liability for schizophrenia. Schizophr Res (2008) 103(1-3):298-310. doi: 10.1016/j.schres.2008.04.038

4. Kiang M, Braff DL, Sprock J, Light GA. The relationship between preattentive sensory processing deficits and age in schizophrenia patients. Clin Neurophysiol (2009) 120(11):1949-57. doi: 10.1016/j.clinph.2009.08.019

5. Leitman DI, Foxe JJ, Butler PD, Saperstein A, Revheim N, Javitt DC. Sensory contributions to impaired prosodic processing in schizophrenia. Biol Psychiatry (2005) 58(1):56-61. doi: 10.1016/j.biopsych.2005.02.034

6. Leitman DI, Sehatpour P, Higgins BA, Foxe JJ, Silipo G, Javitt DC. Sensory deficits and distributed hierarchical dysfunction in schizophrenia. Am J Psychiatry (2010) 167(7):818-27. doi: 10.1176/appi.ajp.2010.09030338

7. Javitt DC. When doors of perception close: bottom-up models of disrupted cognition in schizophrenia. Annu Rev Clin Psychol (2009) 5:249-75. doi: 10.1146/annurev.clinpsy.032408.153502

8. Braff DL, Light GA. Preattentional and attentional cognitive deficits as targets for treating schizophrenia. Psychopharmacol (Berl) (2004) 174(1):75-85. doi: 10.1007/s00213-004-1848-0

9. Rissling AJ, Miyakoshi M, Sugar CA, Braff DL, Makeig S, Light GA. Cortical substrates and functional correlates of auditory deviance processing deficits in schizophrenia. NeuroImage Clin (2014) 6:424-37. doi: 10.1016/j.nicl. 2014.09.006

10. Kirihara K, Rissling AJ, Swerdlow NR, Braff DL, Light GA. Hierarchical organization of gamma and theta oscillatory dynamics in schizophrenia. Biol Psychiatry (2012) 71(10):873-80. doi: 10.1016/j.biopsych.2012.01.016

11. Javitt DC, Freedman R. Sensory processing dysfunction in the personal experience and neuronal machinery of schizophrenia. Am J Psychiatry (2015) 172(1):17-31. doi: 10.1176/appi.ajp.2014.13121691

12. Rissling AJ, Braff DL, Swerdlow NR, Hellemann G, Rassovsky Y, Sprock J, et al. Disentangling early sensory information processing deficits in schizophrenia. Clin Neurophysiol (2012) 123(10):1942-9. doi: 10.1016/ j.clinph.2012.02.079

13. Naatanen R, Gaillard AW, Mantysalo S. Early selective-attention effect on evoked potential reinterpreted. Acta Psychol (Amst) (1978) 42(4):313-29. doi: 10.1016/0001-6918(78)90006-9

14. Light GA, Swerdlow NR, Thomas ML, Calkins ME, Green MF, Greenwood TA, et al. Validation of mismatch negativity and P3a for use in multi-site studies of schizophrenia: characterization of demographic, clinical, have demonstrated potential for MMN to be used as an endophenotype. CSP and LICI may also represent promising biological targets for examining sensory processing deficits in schizophrenia, with accumulating evidence supporting their suitability to be used as endophenotypes as well. Future studies further investigating these markers may yield important findings for the identification of biomarkers in schizophrenia.

\section{AUTHOR CONTRIBUTIONS}

$\mathrm{HK}, \mathrm{DB}$, and $\mathrm{ZD}$ took part in the literature review, manuscript writing and revision of the manuscript. All authors contributed to the article and approved the submitted version.

cognitive, and functional correlates in COGS-2. Schizophr Res (2015) 163 (1-3):63-72. doi: 10.1016/j.schres.2014.09.042

15. Valls-Sole J, Pascual-Leone A, Wassermann EM, Hallett M. Human motor evoked responses to paired transcranial magnetic stimuli. Electroencephalogr Clin Neurophysiol (1992) 85(6):355-64. doi: 10.1016/0168-5597(92)90048-G

16. Nakamura H, Kitagawa H, Kawaguchi $Y$, Tsuji H. Intracortical facilitation and inhibition after transcranial magnetic stimulation in conscious humans. J Physiol (1997) 498( Pt 3):817-23. doi: 10.1113/jphysiol.1997.sp021905

17. Sanger TD, Garg RR, Chen R. Interactions between two different inhibitory systems in the human motor cortex. J Physiol (2001) 530(Pt 2):307-17. doi: 10.1111/j.1469-7793.2001.0307l.x

18. Daskalakis ZJ, Christensen BK, Chen R, Fitzgerald PB, Zipursky RB, Kapur S. Effect of antipsychotics on cortical inhibition using transcranial magnetic stimulation. Psychopharmacol (Berl) (2003) 170(3):255-62. doi: 10.1007/ s00213-003-1548-1

19. Joshi YB, Breitenstein B, Tarasenko M, Thomas ML, Chang WL, Sprock J, et al. Mismatch negativity impairment is associated with deficits in identifying real-world environmental sounds in schizophrenia. Schizophr Res (2018) 191:5-9. doi: 10.1016/j.schres.2017.05.020

20. Garrido MI, Kilner JM, Stephan KE, Friston KJ. The mismatch negativity: a review of underlying mechanisms. Clin Neurophysiol (2009) 120(3):453-63. doi: 10.1016/j.clinph.2008.11.029

21. Fulham WR, Michie PT, Ward PB, Rasser PE, Todd J, Johnston PJ, et al. Mismatch negativity in recent-onset and chronic schizophrenia: a current source density analysis. PloS One (2014) 9(6):e100221. doi: 10.1371/ journal.pone.0100221

22. Light GA, Braff DL. Mismatch negativity deficits are associated with poor functioning in schizophrenia patients. Arch Gen Psychiatry (2005) 62 (2):127-36. doi: 10.1001/archpsyc.62.2.127

23. Umbricht D, Krljes S. Mismatch negativity in schizophrenia: a metaanalysis. Schizophr Res (2005) 76(1):1-23. doi: 10.1016/j.schres.2004.12.002

24. Potter D, Summerfelt A, Gold J, Buchanan RW. Review of clinical correlates of P50 sensory gating abnormalities in patients with schizophrenia. Schizophr Bull (2006) 32(4):692-700. doi: 10.1093/schbul/sbj050

25. Croft RJ, Lee A, Bertolot J, Gruzelier JH. Associations of P50 suppression and desensitization with perceptual and cognitive features of "unreality" in schizotypy. Biol Psychiatry (2001) 50(6):441-6. doi: 10.1016/S0006-3223(01)01082-4

26. Cullum CM, Harris JG, Waldo MC, Smernoff E, Madison A, Nagamoto HT, et al. Neurophysiological and neuropsychological evidence for attentional dysfunction in schizophrenia. Schizophr Res (1993) 10(2):131-41. doi: 10.1016/0920-9964(93)90048-N

27. Guterman Y, Josiassen RC. Sensory gating deviance in schizophrenia in the context of task related effects. Int J Psychophysiol (1994) 18(1):1-12. doi: 10.1016/0167-8760(84)90010-2

28. Vinogradov S, Solomon S, Ober BA, Biggins CA, Shenaut GK, Fein G. Do semantic priming effects correlate with sensory gating in schizophrenia? Biol Psychiatry (1996) 39(9):821-4. doi: 10.1016/0006-3223(95)00571-4 
29. Adler LE, Olincy A, Waldo M, Harris JG, Griffith J, Stevens K, et al. Schizophrenia, sensory gating, and nicotinic receptors. Schizophr Bull (1998) 24(2):189-202. doi: 10.1093/oxfordjournals.schbul.a033320

30. Erwin RJ, Turetsky BI, Moberg P, Gur RC, Gur RE. P50 abnormalities in schizophrenia: relationship to clinical and neuropsychological indices of attention. Schizophr Res (1998) 33(3):157-67. doi: 10.1016/S0920-9964(98) 00075-9

31. Adler LE, Pachtman E, Franks RD, Pecevich M, Waldo MC, Freedman R. Neurophysiological evidence for a defect in neuronal mechanisms involved in sensory gating in schizophrenia. Biol Psychiatry (1982) 17(6):639-54.

32. Boutros N, Zouridakis G, Rustin T, Peabody C, Warner D. The P50 component of the auditory evoked potential and subtypes of schizophrenia. Psychiatry Res (1993) 47(3):243-54. doi: 10.1016/0165-1781(93)90082-R

33. Boutros NN, Overall J, Zouridakis G. Test-retest reliability of the P50 midlatency auditory evoked response. Psychiatry Res (1991) 39(2):181-92. doi: 10.1016/0165-1781(91)90086-5

34. Braff DL, Light GA, Swerdlow NR. Prepulse inhibition and P50 suppression are both deficient but not correlated in schizophrenia patients. Biol Psychiatry (2007) 61(10):1204-7. doi: 10.1016/j.biopsych. 2006.08.015

35. Clementz BA, Blumenfeld LD. Multichannel electroencephalographic assessment of auditory evoked response suppression in schizophrenia. Exp Brain Res (2001) 139(4):377-90. doi: 10.1007/s002210100744

36. Clementz BA, Geyer MA, Braff DL. Poor P50 suppression among schizophrenia patients and their first-degree biological relatives. Am J Psychiatry (1998) 155(12):1691-4. doi: 10.1176/ajp.155.12.1691

37. Freedman R, Adler LE, Waldo MC, Pachtman E, Franks RD. Neurophysiological evidence for a defect in inhibitory pathways in schizophrenia: comparison of medicated and drug-free patients. Biol Psychiatry (1983) 18(5):537-51.

38. Judd LL, McAdams L, Budnick B, Braff DL. Sensory gating deficits in schizophrenia: new results. Am J Psychiatry (1992) 149(4):488-93. doi: 10.1176/ajp.149.4.488

39. Sanchez-Morla EM, Garcia-Jimenez MA, Barabash A, Martinez-Vizcaino V, Mena J, Cabranes-Diaz JA, et al. P50 sensory gating deficit is a common marker of vulnerability to bipolar disorder and schizophrenia. Acta Psychiatr Scand (2008) 117(4):313-8. doi: 10.1111/j.1600-0447.2007.01141.x

40. Daskalakis ZJ, Fitzgerald PB, Christensen BK. The role of cortical inhibition in the pathophysiology and treatment of schizophrenia. Brain Res Rev (2007) 56(2):427-42. doi: 10.1016/j.brainresrev.2007.09.006

41. Daskalakis ZJ, Christensen BK, Chen R, Fitzgerald PB, Zipursky RB, Kapur S. Evidence for impaired cortical inhibition in schizophrenia using transcranial magnetic stimulation. Arch Gen Psychiatry (2002) 59(4):347-54. doi: 10.1001/ archpsyc.59.4.347

42. Nagamoto HT, Adler LE, Hea RA, Griffith JM, McRae KA, Freedman R. Gating of auditory P50 in schizophrenics: unique effects of clozapine. Biol Psychiatry (1996) 40(3):181-8. doi: 10.1016/0006-3223(95)00371-1

43. Ringel TM, Heidrich A, Jacob CP, Pfuhlmann B, Stoeber G, Fallgatter AJ. Sensory gating deficit in a subtype of chronic schizophrenic patients. Psychiatry Res (2004) 125(3):237-45. doi: 10.1016/j.psychres.2004.01.004

44. Turetsky BI, Bilker WB, Siegel SJ, Kohler CG, Gur RE. Profile of auditory information-processing deficits in schizophrenia. Psychiatry Res (2009) 165 (1-2):27-37. doi: 10.1016/j.psychres.2008.04.013

45. Braff DL, Greenwood TA, Swerdlow NR, Light GA, Schork NJ. Investigators of the Consortium on the Genetics of S. Advances in endophenotyping schizophrenia. World Psychiatry (2008) 7(1):11-8. doi: 10.1002/j.20515545.2008.tb00140.x

46. Ross RG, Freedman R. Endophenotypes in Schizophrenia for the Perinatal Period: Criteria for Validation. Schizophr Bull (2015) 41(4):824-34. doi: 10.1093/schbul/sbv054

47. da Cruz JR, Favrod O, Roinishvili M, Chkonia E, Brand A, Mohr C, et al. EEG microstates are a candidate endophenotype for schizophrenia. Nat Commun (2020) 11(1):3089. doi: 10.1038/s41467-020-16914-1

48. Castelnovo A, Zago M, Casetta C, Zangani C, Donati F, Canevini M, et al. Slow wave oscillations in Schizophrenia First-Degree Relatives: A confirmatory analysis and feasibility study on slow wave traveling. Schizophr Res (2020) 221:37-43. doi: 10.1016/j.schres.2020.03.025
49. Green MF, Nuechterlein KH, Gold JM, Barch DM, Cohen J, Essock S, et al. Approaching a consensus cognitive battery for clinical trials in schizophrenia: the NIMH-MATRICS conference to select cognitive domains and test criteria. Biol Psychiatry (2004) 56(5):301-7. doi: 10.1016/ j.biopsych.2004.06.023

50. Min B, Kim M, Lee J, Byun JI, Chu K, Jung KY, et al. Prediction of individual responses to electroconvulsive therapy in patients with schizophrenia: Machine learning analysis of resting-state electroencephalography. Schizophr Res (2020) 216:147-53. doi: 10.1016/j.schres.2019.12.012

51. Li A, Zalesky A, Yue W, Howes O, Yan H, Liu Y, et al. A neuroimaging biomarker for striatal dysfunction in schizophrenia. Nat Med (2020) 26 (4):558-65. doi: 10.1038/s41591-020-0793-8

52. Calkins ME, Dobie DJ, Cadenhead KS, Olincy A, Freedman R, Green MF, et al. The Consortium on the Genetics of Endophenotypes in Schizophrenia: model recruitment, assessment, and endophenotyping methods for a multisite collaboration. Schizophr Bull (2007) 33(1):33-48. doi: 10.1093/schbul/sbl044

53. Turetsky BI, Calkins ME, Light GA, Olincy A, Radant AD, Swerdlow NR. Neurophysiological endophenotypes of schizophrenia: the viability of selected candidate measures. Schizophr Bull (2007) 33(1):69-94. doi: $10.1093 / \mathrm{schbul} / \mathrm{sbl} 060$

54. Francisco AA, Foxe JJ, Horsthuis DJ, DeMaio D, Molholm S. Assessing auditory processing endophenotypes associated with Schizophrenia in individuals with 22q11.2 deletion syndrome. Transl Psychiatry (2020) 10 (1):85. doi: 10.1038/s41398-020-0764-3

55. Keefe RS, Bilder RM, Davis SM, Harvey PD, Palmer BW, Gold JM, et al. Neurocognitive effects of antipsychotic medications in patients with chronic schizophrenia in the CATIE Trial. Arch Gen Psychiatry (2007) 64(6):633-47. doi: 10.1001/archpsyc.64.6.633

56. Lavoie S, Murray MM, Deppen P, Knyazeva MG, Berk M, Boulat O, et al. Glutathione precursor, $\mathrm{N}$-acetyl-cysteine, improves mismatch negativity in schizophrenia patients. Neuropsychopharmacology (2008) 33(9):2187-99. doi: $10.1038 /$ sj.npp.1301624

57. Umbricht D, Koller R, Vollenweider FX, Schmid L. Mismatch negativity predicts psychotic experiences induced by NMDA receptor antagonist in healthy volunteers. Biol Psychiatry (2002) 51(5):400-6. doi: 10.1016/S00063223(01)01242-2

58. Light GA, Swerdlow NR, Rissling AJ, Radant A, Sugar CA, Sprock J, et al. Characterization of neurophysiologic and neurocognitive biomarkers for use in genomic and clinical outcome studies of schizophrenia. PloS One (2012) 7 (7):e39434. doi: 10.1371/journal.pone.0039434

59. Xia L, Wang D, Wang J, Xu H, Huo L, Tian Y, et al. Association of cognitive and P50 suppression deficits in chronic patients with schizophrenia. Clin Neurophysiol (2020) 131(3):725-33. doi: 10.1016/j.clinph.2019.12.405

60. Best MW, Milanovic M, Shamblaw AL, Muere A, Lambe LJ, Hong IK, et al. An examination of the moderating effects of neurophysiology on treatment outcomes from cognitive training in schizophrenia-spectrum disorders. Int $J$ Psychophysiol (2020) 154:59-66. doi: 10.1016/j.ijpsycho.2019.02.004

61. Escera C, Alho K, Schroger E, Winkler I. Involuntary attention and distractibility as evaluated with event-related brain potentials. Audiol Neurootol (2000) 5(3-4):151-66. doi: 10.1159/000013877

62. Schroger E, Wolff C. Attentional orienting and reorienting is indicated by human event-related brain potentials. Neuroreport (1998) 9(15):3355-8. doi: 10.1097/00001756-199810260-00003

63. Kawakubo Y, Kamio S, Nose T, Iwanami A, Nakagome K, Fukuda M, et al. Phonetic mismatch negativity predicts social skills acquisition in schizophrenia. Psychiatry Res (2007) 152(2-3):261-5. doi: 10.1016/ j.psychres.2006.02.010

64. Rasser PE, Schall U, Todd J, Michie PT, Ward PB, Johnston P, et al. Gray matter deficits, mismatch negativity, and outcomes in schizophrenia. Schizophr Bull (2011) 37(1):131-40. doi: 10.1093/schbul/sbp060

65. Tarasenko MA, Swerdlow NR, Makeig S, Braff DL, Light GA. The auditory brain-stem response to complex sounds: a potential biomarker for guiding treatment of psychosis. Front Psychiatry (2014) 5:142. doi: 10.3389/ fpsyt.2014.00142

66. Catts SV, Shelley AM, Ward PB, Liebert B, McConaghy N, Andrews S, et al. Brain potential evidence for an auditory sensory memory deficit in schizophrenia. Am J Psychiatry (1995) 152(2):213-9. doi: 10.1176/ajp.152.2.213 
67. Brockhaus-Dumke A, Tendolkar I, Pukrop R, Schultze-Lutter F, Klosterkotter J, Ruhrmann S. Impaired mismatch negativity generation in prodromal subjects and patients with schizophrenia. Schizophr Res (2005) 73(2-3):297-310. doi: 10.1016/j.schres.2004.05.016

68. Bodatsch M, Ruhrmann S, Wagner M, Muller R, Schultze-Lutter F, Frommann I, et al. Prediction of psychosis by mismatch negativity. Biol Psychiatry (2011) 69(10):959-66. doi: 10.1016/j.biopsych.2010.09.057

69. Kirino E, Inoue R. The relationship of mismatch negativity to quantitative EEG and morphological findings in schizophrenia. J Psychiatr Res (1999) 33 (5):445-56. doi: 10.1016/S0022-3956(99)00012-6

70. Shelley AM, Ward PB, Catts SV, Michie PT, Andrews S, McConaghy N. Mismatch negativity: an index of a preattentive processing deficit in schizophrenia. Biol Psychiatry (1991) 30(10):1059-62. doi: 10.1016/00063223(91)90126-7

71. Javitt DC, Steinschneider M, Schroeder CE, Vaughan HGJr., Arezzo JC. Detection of stimulus deviance within primate primary auditory cortex: intracortical mechanisms of mismatch negativity (MMN) generation. Brain Res (1994) 667(2):192-200. doi: 10.1016/0006-8993(94)91496-6

72. Javitt DC, Shelley AM, Silipo G, Lieberman JA. Deficits in auditory and visual context-dependent processing in schizophrenia: defining the pattern. Arch Gen Psychiatry (2000) 57(12):1131-7. doi: 10.1001/archpsyc.57.12.1131

73. Michie PT. What has MMN revealed about the auditory system in schizophrenia? Int J Psychophysiol (2001) 42(2):177-94. doi: 10.1016/ S0167-8760(01)00166-0

74. Umbricht D, Koller R, Schmid L, Skrabo A, Grubel C, Huber T, et al. How specific are deficits in mismatch negativity generation to schizophrenia? Biol Psychiatry (2003) 53(12):1120-31. doi: 10.1016/S0006-3223(02)01642-6

75. Salisbury DF, Shenton ME, Griggs CB, Bonner-Jackson A, McCarley RW. Mismatch negativity in chronic schizophrenia and first-episode schizophrenia. Arch Gen Psychiatry (2002) 59(8):686-94. doi: 10.1001/ archpsyc.59.8.686

76. Oknina LB, Wild-Wall N, Oades RD, Juran SA, Ropcke B, Pfueller U, et al. Frontal and temporal sources of mismatch negativity in healthy controls, patients at onset of schizophrenia in adolescence and others at 15 years after onset. Schizophr Res (2005) 76(1):25-41. doi: 10.1016/j.schres.2004.10.003

77. Oades RD, Wild-Wall N, Juran SA, Sachsse J, Oknina LB, Ropcke B. Auditory change detection in schizophrenia: sources of activity, related neuropsychological function and symptoms in patients with a first episode in adolescence, and patients 14 years after an adolescent illness-onset. $B M C$ Psychiatry (2006) 6:7. doi: 10.1186/1471-244X-6-7

78. Salisbury DF, Kuroki N, Kasai K, Shenton ME, McCarley RW. Progressive and interrelated functional and structural evidence of post-onset brain reduction in schizophrenia. Arch Gen Psychiatry (2007) 64(5):521-9. doi: 10.1001/archpsyc.64.5.521

79. Umbricht DS, Bates JA, Lieberman JA, Kane JM, Javitt DC. Electrophysiological indices of automatic and controlled auditory information processing in first-episode, recent-onset and chronic schizophrenia. Biol Psychiatry (2006) 59(8):762-72. doi: 10.1016/ j.biopsych.2005.08.030

80. Hermens DF, Ward PB, Hodge MA, Kaur M, Naismith SL, Hickie IB. Impaired MMN/P3a complex in first-episode psychosis: cognitive and psychosocial associations. Prog Neuropsychopharmacol Biol Psychiatry (2010) 34(6):822-9. doi: 10.1016/j.pnpbp.2010.03.019

81. Jahshan C, Cadenhead KS, Rissling AJ, Kirihara K, Braff DL, Light GA. Automatic sensory information processing abnormalities across the illness course of schizophrenia. Psychol Med (2012) 42(1):85-97. doi: 10.1017/ S0033291711001061

82. Atkinson RJ, Michie PT, Schall U. Duration mismatch negativity and P3a in first-episode psychosis and individuals at ultra-high risk of psychosis. Biol Psychiatry (2012) 71(2):98-104. doi: 10.1016/j.biopsych.2011.08.023

83. Grillon C, Courchesne E, Ameli R, Elmasian R, Braff D. Effects of rare nontarget stimuli on brain electrophysiological activity and performance. Int $J$ Psychophysiol (1990) 9(3):257-67. doi: 10.1016/0167-8760(90)90058-L

84. Grillon C, Courchesne E, Ameli R, Geyer MA, Braff DL. Increased distractibility in schizophrenic patients. Electrophysiologic and behavioral evidence. Arch Gen Psychiatry (1990) 47(2):171-9. doi: 10.1001/ archpsyc. 1990.01810140071010
85. Grzella I, Muller BW, Oades RD, Bender S, Schall U, Zerbin D, et al. Novelty-elicited mismatch negativity in patients with schizophrenia on admission and discharge. J Psychiatry Neurosci (2001) 26(3):235-46.

86. Mathalon DH, Ford JM, Pfefferbaum A. Trait and state aspects of P300 amplitude reduction in schizophrenia: a retrospective longitudinal study. Biol Psychiatry (2000) 47(5):434-49. doi: 10.1016/S0006-3223(99)00277-2

87. Fisher DJ, Labelle A, Knott VJ. Alterations of mismatch negativity (MMN) in schizophrenia patients with auditory hallucinations experiencing acute exacerbation of illness. Schizophr Res (2012) 139(1-3):237-45. doi: 10.1016/ j.schres.2012.06.004

88. Light GA, Swerdlow NR. Future clinical uses of neurophysiological biomarkers to predict and monitor treatment response for schizophrenia. Ann N Y Acad Sci (2015) 1344:105-19. doi: 10.1111/nyas.12730

89. Hall MH, Schulze K, Rijsdijk F, Picchioni M, Ettinger U, Bramon E, et al. Heritability and reliability of P300, P50 and duration mismatch negativity. Behav Genet (2006) 36(6):845-57. doi: 10.1007/s10519-006-9091-6

90. Erickson MA, Ruffle A, Gold JM. A Meta-Analysis of Mismatch Negativity in Schizophrenia: From Clinical Risk to Disease Specificity and Progression. Biol Psychiatry (2016) 79(12):980-7. doi: 10.1016/j.biopsych.2015.08.025

91. Baldeweg T, Wong D, Stephan KE. Nicotinic modulation of human auditory sensory memory: Evidence from mismatch negativity potentials. Int $J$ Psychophysiol (2006) 59(1):49-58. doi: 10.1016/j.ijpsycho.2005.07.014

92. Kargel C, Sartory G, Kariofillis D, Wiltfang J, Muller BW. Mismatch negativity latency and cognitive function in schizophrenia. PloS One (2014) 9(4):e84536. doi: 10.1371/journal.pone.0084536

93. Todd J, Michie PT, Schall U, Karayanidis F, Yabe H, Naatanen R. Deviant matters: duration, frequency, and intensity deviants reveal different patterns of mismatch negativity reduction in early and late schizophrenia. Biol Psychiatry (2008) 63(1):58-64. doi: 10.1016/j.biopsych.2007.02.016

94. Youn T, Park HJ, Kim JJ, Kim MS, Kwon JS. Altered hemispheric asymmetry and positive symptoms in schizophrenia: equivalent current dipole of auditory mismatch negativity. Schizophr Res (2003) 59(2-3):253-60. doi: 10.1016/S0920-9964(02)00154-8

95. Thonnessen H, Zvyagintsev M, Harke KC, Boers F, Dammers J, Norra C, et al. Optimized mismatch negativity paradigm reflects deficits in schizophrenia patients. A combined EEG and MEG study. Biol Psychol (2008) 77(2):205-16. doi: 10.1016/j.biopsycho.2007.10.009

96. Fisher DJ, Grant B, Smith DM, Borracci G, Labelle A, Knott VJ. Effects of auditory hallucinations on the mismatch negativity $(\mathrm{MMN})$ in schizophrenia as measured by a modified 'optimal' multi-feature paradigm. Int J Psychophysiol (2011) 81(3):245-51. doi: 10.1016/j.ijpsycho.2011.06.018

97. Schall U, Catts SV, Karayanidis F, Ward PB. Auditory event-related potential indices of fronto-temporal information processing in schizophrenia syndromes: valid outcome prediction of clozapine therapy in a three-year follow-up. Int J Neuropsychopharmacol (1999) 2(2):83-93. doi: 10.1017/ S1461145799001418

98. Kasai K, Okazawa K, Nakagome K, Hiramatsu K, Hata A, Fukuda M, et al. Mismatch negativity and N2b attenuation as an indicator for dysfunction of the preattentive and controlled processing for deviance detection in schizophrenia: a topographic event-related potential study. Schizophr Res (1999) 35(2):141-56. doi: 10.1016/S0920-9964(98)00116-9

99. Light GA, Braff DL. Stability of mismatch negativity deficits and their relationship to functional impairments in chronic schizophrenia. Am J Psychiatry (2005) 162(9):1741-3. doi: 10.1176/appi.ajp.162.9.1741

100. Earls HA, Curran T, Mittal V. A Meta-analytic Review of Auditory EventRelated Potential Components as Endophenotypes for Schizophrenia: Perspectives From First-Degree Relatives. Schizophr Bull (2016) 42 (6):1504-16. doi: 10.1093/schbul/sbw047

101. Baldeweg T, Klugman A, Gruzelier J, Hirsch SR. Mismatch negativity potentials and cognitive impairment in schizophrenia. Schizophr Res (2004) 69(2-3):203-17. doi: 10.1016/j.schres.2003.09.009

102. Naatanen R, Kujala T, Kreegipuu K, Carlson S, Escera C, Baldeweg T, et al. The mismatch negativity: an index of cognitive decline in neuropsychiatric and neurological diseases and in ageing. Brain (2011) 134(Pt 12):3435-53. doi: 10.1093/brain/awr064

103. Light GA, Swerdlow NR, Braff DL. Preattentive sensory processing as indexed by the MMN and P3a brain responses is associated with cognitive 
and psychosocial functioning in healthy adults. J Cognit Neurosci (2007) 19 (10):1624-32. doi: 10.1162/jocn.2007.19.10.1624

104. Friedman T, Sehatpour P, Dias E, Perrin M, Javitt DC. Differential relationships of mismatch negativity and visual p1 deficits to premorbid characteristics and functional outcome in schizophrenia. Biol Psychiatry (2012) 71(6):521-9. doi: 10.1016/j.biopsych.2011.10.037

105. Toyomaki A, Kusumi I, Matsuyama T, Kako Y, Ito K, Koyama T. Tone duration mismatch negativity deficits predict impairment of executive function in schizophrenia. Prog Neuropsychopharmacol Biol Psychiatry (2008) 32(1):95-9. doi: 10.1016/j.pnpbp.2007.07.020

106. Kawakubo Y, Kasai K, Kudo N, Rogers MA, Nakagome K, Itoh K, et al. Phonetic mismatch negativity predicts verbal memory deficits in schizophrenia. Neuroreport (2006) 17(10):1043-6. doi: 10.1097/01.wnr.0000221828.10846.ba

107. Perez VB, Tarasenko M, Miyakoshi M, Pianka ST, Makeig SD, Braff DL, et al. Mismatch Negativity is a Sensitive and Predictive Biomarker of Perceptual Learning During Auditory Cognitive Training in Schizophrenia. Neuropsychopharmacology (2017) 42(11):2206-13. doi: 10.1038/npp.2017.25

108. Wynn JK, Sugar C, Horan WP, Kern R, Green MF. Mismatch negativity, social cognition, and functioning in schizophrenia patients. Biol Psychiatry (2010) 67(10):940-7. doi: 10.1016/j.biopsych.2009.11.024

109. Lee SH, Sung K, Lee KS, Moon E, Kim CG. Mismatch negativity is a stronger indicator of functional outcomes than neurocognition or theory of mind in patients with schizophrenia. Prog Neuropsychopharmacol Biol Psychiatry (2014) 48:213-9. doi: 10.1016/j.pnpbp.2013.10.010

110. Nevado JJ, Penalvo GC, Sanchez JC, Mochon MC, Dorado RM, Navarro MV. Optimisation and validation of a new CE method for the determination of lansoprazole enantiomers in pharmaceuticals. Electrophoresis (2009) 30 (16):2940-6. doi: 10.1002/elps.200800810

111. Bramon E, Rabe-Hesketh S, Sham P, Murray RM, Frangou S. Meta-analysis of the P300 and P50 waveforms in schizophrenia. Schizophr Res (2004) 70(23):315-29. doi: 10.1016/j.schres.2004.01.004

112. Boutros NN, Brockhaus-Dumke A, Gjini K, Vedeniapin A, Elfakhani M, Burroughs S, et al. Sensory-gating deficit of the N100 mid-latency auditory evoked potential in medicated schizophrenia patients. Schizophr Res (2009) 113(2-3):339-46. doi: 10.1016/j.schres.2009.05.019

113. Santos JL, Sanchez-Morla EM, Aparicio A, Garcia-Jimenez MA, Villanueva C, Martinez-Vizcaino V, et al. P50 gating in deficit and nondeficit schizophrenia. Schizophr Res (2010) 119(1-3):183-90. doi: 10.1016/j.schres.2010.01.010

114. de Wilde OM, Bour LJ, Dingemans PM, Koelman JH, Linszen DH. A metaanalysis of P50 studies in patients with schizophrenia and relatives: differences in methodology between research groups. Schizophr Res (2007) 97(1-3):137-51. doi: 10.1016/j.schres.2007.04.028

115. Roth WT, Pfefferbaum A, Kelly AF, Berger PA, Kopell BS. Auditory eventrelated potentials in schizophrenia and depression. Psychiatry Res (1981) 4 (2):199-212. doi: 10.1016/0165-1781(81)90023-8

116. Freedman R, Coon H, Myles-Worsley M, Orr-Urtreger A, Olincy A, Davis A, et al. Linkage of a neurophysiological deficit in schizophrenia to a chromosome 15 locus. Proc Natl Acad Sci U S A (1997) 94(2):587-92. doi: 10.1073/pnas.94.2.587

117. Leonard S, Gault J, Hopkins J, Logel J, Vianzon R, Short M, et al. Association of promoter variants in the alpha7 nicotinic acetylcholine receptor subunit gene with an inhibitory deficit found in schizophrenia. Arch Gen Psychiatry (2002) 59(12):1085-96. doi: 10.1001/archpsyc.59.12.1085

118. Freedman R, Adams CE, Adler LE, Bickford PC, Gault J, Harris JG, et al. Inhibitory neurophysiological deficit as a phenotype for genetic investigation of schizophrenia. Am J Med Genet (2000) 97(1):58-64. doi: 10.1002/(SICI) 1096-8628(200021)97:1<58::AID-AJMG8>3.0.CO;2-Y

119. Adler LE, Olincy A, Cawthra EM, McRae KA, Harris JG, Nagamoto HT, et al. Varied effects of atypical neuroleptics on P50 auditory gating in schizophrenia patients. Am J Psychiatry (2004) 161(10):1822-8. doi: 10.1176/ajp.161.10.1822

120. Light GA, Geyer MA, Clementz BA, Cadenhead KS, Braff DL. Normal P50 suppression in schizophrenia patients treated with atypical antipsychotic medications. Am J Psychiatry (2000) 157(5):767-71. doi: 10.1176/ appi.ajp.157.5.767

121. Smith AK, Edgar JC, Huang M, Lu BY, Thoma RJ, Hanlon FM, et al. Cognitive abilities and 50- and $100-\mathrm{msec}$ paired-click processes in schizophrenia. Am J Psychiatry (2010) 167(10):1264-75. doi: 10.1176/ appi.ajp.2010.09071059
122. Smith DM, Grant B, Fisher DJ, Borracci G, Labelle A, Knott VJ. Auditory verbal hallucinations in schizophrenia correlate with P50 gating. Clin Neurophysiol (2013) 124(7):1329-35. doi: 10.1016/j.clinph.2013.02.004

123. Kumari V, Peters ER, Fannon D, Premkumar P, Aasen I, Cooke MA, et al. Uncontrollable voices and their relationship to gating deficits in schizophrenia. Schizophr Res (2008) 101(1-3):185-94. doi: 10.1016/j.schres.2007.12.481

124. Faugere M, Micoulaud-Franchi JA, Boyer L, Cermolacce M, Richieri R, Faget $\mathrm{C}$, et al. Does sensory gating have a protective effect against hallucinatory behavior in schizophrenia? Clin Neurophysiol (2016) 127(2):1746-8. doi: 10.1016/j.clinph.2015.10.031

125. Arnfred SM, Chen AC. Exploration of somatosensory P50 gating in schizophrenia spectrum patients: reduced P50 amplitude correlates to social anhedonia. Psychiatry Res (2004) 125(2):147-60. doi: 10.1016/ j.psychres.2003.12.008

126. Louchart-de la Chapelle S, Nkam I, Houy E, Belmont A, Menard JF, Roussignol AC, et al. A concordance study of three electrophysiological measures in schizophrenia. Am J Psychiatry (2005) 162(3):466-74. doi: 10.1176/appi.ajp.162.3.466

127. Waldo MC, Adler LE, Freedman R. Defects in auditory sensory gating and their apparent compensation in relatives of schizophrenics. Schizophr Res (1988) 1(1):19-24. doi: 10.1016/0920-9964(88)90035-7

128. Zhu XL, Tan SP, Wang ZR, Zhang JG, Li D, Fan FM, et al. P50 suppression deficits and psychopathology in Han Chinese patients with schizophrenia. Neurosci Lett (2017) 653:346-50. doi: 10.1016/j.neulet.2017.06.009

129. Adler LE, Waldo MC, Tatcher A, Cawthra E, Baker N, Freedman R. Lack of relationship of auditory gating defects to negative symptoms in schizophrenia. Schizophr Res (1990) 3(2):131-8. doi: 10.1016/0920-9964(90)90046-A

130. Yee CM, Nuechterlein KH, Morris SE, White PM. P50 suppression in recentonset schizophrenia: clinical correlates and risperidone effects. J Abnorm Psychol (1998) 107(4):691-8. doi: 10.1037/0021-843X.107.4.691

131. Thoma RJ, Hanlon FM, Moses SN, Ricker D, Huang M, Edgar C, et al. M50 sensory gating predicts negative symptoms in schizophrenia. Schizophr Res (2005) 73(2-3):311-8. doi: 10.1016/j.schres.2004.07.001

132. Chen L, Ding Y, Cagniard B, Van Laar AD, Mortimer A, Chi W, et al. Unregulated cytosolic dopamine causes neurodegeneration associated with oxidative stress in mice. J Neurosci (2008) 28(2):425-33. doi: 10.1523/ JNEUROSCI.3602-07.2008

133. Louchart-de la Chapelle S, Levillain D, Menard JF, Van der Elst A, Allio G, Haouzir S, et al. P50 inhibitory gating deficit is correlated with the negative symptomatology of schizophrenia. Psychiatry Res (2005) 136(1):27-34. doi: 10.1016/j.psychres.2003.04.001

134. Schulze KK, Hall MH, McDonald C, Marshall N, Walshe M, Murray RM, et al. P50 auditory evoked potential suppression in bipolar disorder patients with psychotic features and their unaffected relatives. Biol Psychiatry (2007) 62(2):121-8. doi: 10.1016/j.biopsych.2006.08.006

135. Olincy A, Martin L. Diminished suppression of the P50 auditory evoked potential in bipolar disorder subjects with a history of psychosis. Am J Psychiatry (2005) 162(1):43-9. doi: 10.1176/appi.ajp.162.1.43

136. Thomas C, vom Berg I, Rupp A, Seidl U, Schroder J, Roesch-Ely D, et al. P50 gating deficit in Alzheimer dementia correlates to frontal neuropsychological function. Neurobiol Aging (2010) 31(3):416-24. doi: 10.1016/j.neurobiolaging. 2008.05.002

137. Myles-Worsley M, Coon H, Byerley W, Waldo M, Young D, Freedman R. Developmental and genetic influences on the P50 sensory gating phenotype. Biol Psychiatry (1996) 39(4):289-95. doi: 10.1016/0006-3223(95)00134-4

138. Young DA, Waldo M, Rutledge JH3, Freedman R. Heritability of inhibitory gating of the P50 auditory-evoked potential in monozygotic and dizygotic twins. Neuropsychobiology (1996) 33(3):113-7. doi: 10.1159/000119260

139. Greenwood TA, Braff DL, Light GA, Cadenhead KS, Calkins ME, Dobie DJ, et al. Initial heritability analyses of endophenotypic measures for schizophrenia: the consortium on the genetics of schizophrenia. Arch Gen Psychiatry (2007) 64(11):1242-50. doi: 10.1001/archpsyc.64.11.1242

140. Vlcek P, Bob P, Raboch J. Sensory disturbances, inhibitory deficits, and the P50 wave in schizophrenia. Neuropsychiatr Dis Treat (2014) 10:1309-15. doi: 10.2147/NDT.S64219

141. Hamilton HK, Williams TJ, Ventura J, Jasperse LJ, Owens EM, Miller GA, et al. Clinical and cognitive significance of auditory sensory processing 
deficits in Schizophrenia. Am J Psychiatry (2018) 175(3):275-83. doi: 10.1176/appi.ajp.2017.16111203

142. Smucny J, Olincy A, Eichman LC, Lyons E, Tregellas JR. Early sensory processing deficits predict sensitivity to distraction in schizophrenia. Schizophr Res (2013) 147(1):196-200. doi: 10.1016/j.schres.2013.03.025

143. Hsieh MH, Liu K, Liu SK, Chiu MJ, Hwu HG, Chen AC. Memory impairment and auditory evoked potential gating deficit in schizophrenia. Psychiatry Res (2004) 130(2):161-9. doi: 10.1016/j.pscychresns.2002.12.001

144. Cirillo G, Di Pino G, Capone F, Ranieri F, Florio L, Todisco V, et al. Neurobiological after-effects of non-invasive brain stimulation. Brain Stimul (2017) 10(1):1-18. doi: 10.1016/j.brs.2016.11.009

145. Radhu N, de Jesus DR, Ravindran LN, Zanjani A, Fitzgerald PB, Daskalakis ZJ. A meta-analysis of cortical inhibition and excitability using transcranial magnetic stimulation in psychiatric disorders. Clin Neurophysiol (2013) 124 (7):1309-20. doi: 10.1016/j.clinph.2013.01.014

146. Ma J, Leung LS. GABA(B) receptor blockade in the hippocampus affects sensory and sensorimotor gating in Long-Evans rats. Psychopharmacol (Berl) (2011) 217(2):167-76. doi: 10.1007/s00213-011-2274-8

147. Bolton MM, Heaney CF, Murtishaw AS, Sabbagh JJ, Magcalas CM, Kinney JW. Postnatal alterations in GABAB receptor tone produce sensorimotor gating deficits and protein level differences in adulthood. Int J Dev Neurosci (2015) 41:17-27. doi: 10.1016/j.ijdevneu.2014.10.001

148. Daskalakis ZJ, Christensen BK, Fitzgerald PB, Roshan L, Chen R. The mechanisms of interhemispheric inhibition in the human motor cortex. $J$ Physiol (2002) 543(Pt 1):317-26. doi: 10.1113/jphysiol.2002.017673

149. Rogasch NC, Daskalakis ZJ, Fitzgerald PB. Mechanisms underlying longinterval cortical inhibition in the human motor cortex: a TMS-EEG study. $J$ Neurophysiol (2013) 109(1):89-98. doi: 10.1152/jn.00762.2012

150. Cantello R, Gianelli M, Civardi C, Mutani R. Magnetic brain stimulation: the silent period after the motor evoked potential. Neurology (1992) 42 (10):1951-9. doi: 10.1212/WNL.42.10.1951

151. Farzan F, Barr MS, Hoppenbrouwers SS, Fitzgerald PB, Chen R, PascualLeone A, et al. The EEG correlates of the TMS-induced EMG silent period in humans. Neuroimage (2013) 83:120-34. doi: 10.1016/j.neuroimage. 2013.06.059

152. Moller B, Light GA, Fitzgerald PB, Snyder JS, Chen R, Daskalakis ZJ. Relationship between P50 suppression and the cortical silent period. Neuroreport (2007) 18(14):1503-6. doi: 10.1097/WNR.0b013e3282ef6a29

153. McDonnell MN, Orekhov Y, Ziemann U. The role of GABA(B) receptors in intracortical inhibition in the human motor cortex. Exp Brain Res (2006) 173 (1):86-93. doi: 10.1007/s00221-006-0365-2

154. Siebner HR, Dressnandt J, Auer C, Conrad B. Continuous intrathecal baclofen infusions induced a marked increase of the transcranially evoked silent period in a patient with generalized dystonia. Muscle Nerve (1998) 21 (9):1209-12. doi: 10.1002/(SICI) 1097-4598(199809)21:9<1209::AIDMUS15 >3.0.CO;2-M

155. Fitzgerald PB, Brown TL, Daskalakis ZJ, Kulkarni J. A transcranial magnetic stimulation study of inhibitory deficits in the motor cortex in patients with schizophrenia. Psychiatry Res (2002) 114(1):11-22. doi: 10.1016/S0925-4927 (02)00002-1

156. Mehta UM, Thirthalli J, Basavaraju R, Gangadhar BN. Association of intracortical inhibition with social cognition deficits in schizophrenia: Findings from a transcranial magnetic stimulation study. Schizophr Res (2014) 158(1-3):146-50. doi: 10.1016/j.schres.2014.06.043

157. Radhu N, Garcia Dominguez L, Farzan F, Richter MA, Semeralul MO, Chen R, et al. Evidence for inhibitory deficits in the prefrontal cortex in schizophrenia. Brain (2015) 138(Pt 2):483-97. doi: 10.1093/brain/awu360

158. Radhu N, Dominguez LG, Greenwood TA, Farzan F, Semeralul MO, Richter $\mathrm{MA}$, et al. Investigating cortical inhibition in first-degree relatives and probands in Schizophrenia. Sci Rep (2017) 7:43629. doi: 10.1038/srep43629

159. Strube W, Wobrock T, Bunse T, Palm U, Padberg F, Malchow B, et al. Impairments in motor-cortical inhibitory networks across recent-onset and chronic schizophrenia: a cross-sectional TMS Study. Behav Brain Res (2014) 264:17-25. doi: 10.1016/j.bbr.2014.01.041

160. Kaster TS, de Jesus D, Radhu N, Farzan F, Blumberger DM, Rajji TK, et al. Clozapine potentiation of GABA mediated cortical inhibition in treatment resistant schizophrenia. Schizophr Res (2015) 165(2-3):157-62. doi: 10.1016/ j.schres.2015.04.015
161. Frank E, Landgrebe M, Poeppl TB, Schecklmann M, Kreuzer PM, Prasser J, et al. Antipsychotic treatment with quetiapine increases the cortical silent period. Schizophr Res (2014) 156(1):128-32. doi: 10.1016/j.schres. 2014.03.028

162. Liu SK, Fitzgerald PB, Daigle M, Chen R, Daskalakis ZJ. The relationship between cortical inhibition, antipsychotic treatment, and the symptoms of schizophrenia. Biol Psychiatry (2009) 65(6):503-9. doi: 10.1016/ j.biopsych.2008.09.012

163. Schecklmann M, Weidler C, Eichhammer P, Hajak G, Langguth B. Increased short-interval intracortical inhibition in un-medicated patients with schizophrenia. Brain Stimul (2018) 11(5):1080-2. doi: 10.1016/ j.brs.2018.05.003

164. Goodman MS, Bridgman AC, Rabin RA, Blumberger DM, Rajji TK, Daskalakis ZJ, et al. Differential effects of cannabis dependence on cortical inhibition in patients with schizophrenia and non-psychiatric controls. Brain Stimul (2017) 10(2):275-82. doi: 10.1016/j.brs.2016.11.004

165. Hasan A, Nitsche MA, Herrmann M, Schneider-Axmann T, Marshall L, Gruber $\mathrm{O}$, et al. Impaired long-term depression in schizophrenia: a cathodal tDCS pilot study. Brain Stimul (2012) 5(4):475-83. doi: 10.1016/ j.brs.2011.08.004

166. Bentley JN, Irwin ZT, Black SD, Roach ML, Vaden RJ, Gonzalez CL, et al. Subcortical Intermittent Theta-Burst Stimulation (iTBS) increases ThetaPower in Dorsolateral Prefrontal Cortex (DLPFC). Front Neurosci (2020) 14:41. doi: 10.3389/fnins.2020.00041

167. Zewdie E, Ciechanski P, Kuo HC, Giuffre A, Kahl C, King R, et al. Safety and tolerability of transcranial magnetic and direct current stimulation in children: Prospective single center evidence from 3.5 million stimulations. Brain Stimul (2020) 13(3):565-75. doi: 10.1016/j.brs.2019.12.025

168. Bender S, Weisbrod M, Resch F. Which perspectives can endophenotypes and biological markers offer in the early recognition of schizophrenia? J Neural Transm (Vienna) (2007) 114(9):1199-215. doi: 10.1007/s00702-007-0742-4

169. Ricken R, Wiethoff K, Reinhold T, Stamm TJ, Baghai TC, Fisher R, et al. A standardized stepwise drug treatment algorithm for depression reduces direct treatment costs in depressed inpatients - Results from the German Algorithm Project (GAP3). J Affect Disord (2018) 228:173-7. doi: 10.1016/ j.jad.2017.11.051

170. Daskalakis ZJ, George TP. Clozapine, GABA(B), and the treatment of resistant schizophrenia. Clin Pharmacol Ther (2009) 86(4):442-6. doi: 10.1038/clpt.2009.115

171. Hershman KM, Freedman R, Bickford PC. GABAB antagonists diminish the inhibitory gating of auditory response in the rat hippocampus. Neurosci Lett (1995) 190(2):133-6. doi: 10.1016/0304-3940(95)11523-Y

Conflict of Interest: In the last 5 years, ZD has received research and equipment in-kind support for an investigator-initiated study through Brainsway Inc. and Magventure Inc. His work is supported by the Canadian Institutes of Health Research (CIHR), the National Institutes of Mental Health (NIMH), Brain Canada, and the Temerty Family and Grant Family through the Centre for Addiction and Mental Health (CAMH) Foundation and the Campbell Institute DB has received research support from CIHR, NIH, Brain Canada, and the Temerty Family through the CAMH Foundation and the Campbell Family Research Institute. He received research support and in-kind equipment support for an investigator-initiated study from Brainsway Ltd. He is the site principal investigator for three sponsor-initiated studies for Brainsway Ltd. He also receives in-kind equipment support from Magventure for two investigatorinitiated studies. He received medication supplies for an investigator-initiated trial from Indivior.

The remaining author declares that the research was conducted in the absence of any commercial or financial relationships that could be construed as a potential conflict of interest.

Copyright (c) 2020 Kim, Blumberger and Daskalakis. This is an open-access article distributed under the terms of the Creative Commons Attribution License (CC BY). The use, distribution or reproduction in other forums is permitted, provided the original author(s) and the copyright owner(s) are credited and that the original publication in this journal is cited, in accordance with accepted academic practice. No use, distribution or reproduction is permitted which does not comply with these terms. 